\title{
A PERSPECTIVA DO \\ ACOMPANHAMENTO \\ LONGITUDINAL DA \\ APRENDIZAGEM DOS \\ ALUNOS DO ENSINO \\ MÉDIO ATRAVÉS DOS \\ RESULTADOS DO SPAECE
}

FRANCESCA DANIELLE GURGEL DOS SANTOS, MARIA ISABEL FILGUEIRAS LIMA CIASCA

\section{RESUMO}

$O$ artigo inicia-se com a perspectiva do acompanhamento longitudinal da evolução da aprendizagem dos alunos através do Sistema Permanente de Avaliação da Educação Básica do Estado do Ceará (Spaece), aplicada anualmente a todos os alunos do Ensino Médio (EM). Como metodologia, foi adotado o estudo longitudinal amostral dos resultados do Spaece no período 2008-2009, quando em 2008 foram utilizadas as médias de proficiência de Língua Portuguesa e Matemática do 1ํano do EM e em 2009, as médias do $2^{\circ}$ ano do EM. Na oportunidade, são apresentadas as habilidades que os alunos dominam e/ou deveriam dominar nas disciplinas avaliadas, bem como o crescimento longitudinal de uma série para outra e o necessário para o 3a ano do EM no ano 2010, para que este aluno conclua o ano no nível desejado; gráficos com a evolução do percentual de acertos nos descritores avaliados no período em estudo. Após análise, verifica-se quanto os professores precisam se apropriar destes resultados e utilizá-los como ferramenta pedagógica para nortear ações estratégicas eficazes em sua prática docente. 


\section{RESUMEN}

El artículo comienza con la perspectiva del acompañamiento longitudinal de la evolución del aprendizaje de los alumnos a través del Sistema Permanente de Evaluación de la Educación Básica del estado de Ceará (SPAECE), aplicada anualmente a todos los alumnos de la enseñanza media. (EM). Se adoptó como metodología el estudio longitudinal por muestreo de los resultados del SPAECE en el período 2008-2009, en el que se utilizaron los promedios del desempeño en Lengua Portuguesa y Matemática del primer año de la EM (2008) y los promedios del segundo año de la EM (2009). Se presentan las habilidades que los alumnos dominan y/o deberían dominar en las disciplinas evaluadas, así como el crecimiento longitudinal de un año al otro y lo necesario para el 3a año de la EM, en 2010, para que el alumno concluya el año con el nivel deseado. También se presentan gráficos con la evolución del porcentaje de aciertos en los descriptores evaluados en el período estudiado. Después del análisis se verifica cuánto los profesores precisan apropiarse de estos resultados y utilizarlos como herramientas pedagógicas para orientar acciones estratégicas y eficaces en su práctica docente.

PALABRAS CLAVE: EVALUACIÓN DEL APRENDIZAJE •

RENDIMIENTO ESCOLAR・ENSEÑANZA MEDIA • SPAECE.

\section{ABSTRACT}

This article begins with a longitudinal perspective on the evolution of student learning through the Permanent System of Evaluation of Basic Education of the State of Ceará (SPAECE) applied annually to all high school students (HS). The methodology adopted was a longitudinal study with a sampling of the SPAECE 2008-2009 results. In 2008 we used the average proficiency in Portuguese Language and Mathematics for the 1st year of HS and in 2009, the averages for the 2nd year of HS. We present the skills that students master and / or should master in the subjects evaluated, and the longitudinal growth from one grade to the other as well as what is necessary for the 3rd year of HS in 2010 for this student to finish the year at the desired level. We also present charts showing the evolution of the percentage of correct answers in the descriptors evaluated during the period under study. The analysis of the data reveals how much teachers need to take these results into account and use them as a pedagogical tool to create effective strategic actions in their teaching practice. 


\section{INTRODUÇÃO}

A avaliação educacional por um longo tempo limitou seu olhar ao desempenho escolar, a fim de diagnosticar quais eram os problemas de aprendizagem apresentados pelos alunos. Em seguida, a preocupação da avaliação partiu do aluno para o grupo de que este fazia parte, mudando assim o objeto de estudo sem alterar a finalidade do estudo. Posteriormente, a avaliação abrangeu os programas e materiais didáticos utilizados no âmbito escolar, expandindo-se há duas décadas ao sistema educacional com o objetivo de avaliar a qualidade do ensino (ViannA, 1989; 2000).

Uma exemplificação de avaliação do sistema educacional no Brasil é o Sistema Nacional de Avaliação da Educação Básica (Saeb) de abrangência nacional. Vale ressaltar que sua efetividade ao longo de suas edições, desde o ano de 1990, instigou os estados a estabelecer seu próprio sistema de avaliação na perspectiva de garantir às Secretarias de Educação dados fidedignos sobre o desempenho dos estudantes nas disciplinas de Língua Portuguesa e Matemática. Segundo Santos (2010), os dados levantados são primordiais para nortear a tomada de 
decisão de quais políticas públicas deverão ser implementadas para a melhoria do ensino e da aprendizagem alinhada à realidade apresentada pelos resultados.

Desde 1992, vem sendo utilizado no Ceará o Sistema Permanente de Avaliação da Educação Básica (Spaece), o qual evoluiu de tal maneira nestes 19 anos que atualmente avalia censitariamente todos os alunos matriculados no Ensino Médio (EM) nas disciplinas de Língua Portuguesa e Matemática.

Porém, a pouca apropriação dos seus resultados por parte dos professores e gestores inviabiliza sua utilização como ferramenta pedagógica. Este artigo revela a perspectiva de estudar esses resultados longitudinalmente, tornando possível acompanhar ao longo dos três anos do EM o mesmo grupo de alunos. Assim, há como analisar a evolução do desempenho de cada aluno na sua individualidade enquanto aprendiz.

Essa nova perspectiva do Spaece proporcionou aos docentes a possibilidade de identificar quais competências e habilidades foram agregadas ano a ano, além de analisar o crescimento evolutivo nas disciplinas de Língua Portuguesa e Matemática no Spaece. Assim, nos revela ser um importante instrumento a ser inserido no planejamento escolar para nortear a definição de ações estratégicas eficazes que desenvolvam nos alunos as habilidades previstas para cada série/ano do EM.

Os professores podem utilizar o Spaece como ferramenta diagnóstica para melhoria do planejamento e da prática pedagógica, através da compreensão do significado e utilização da média de proficiência da escola por série avaliada. Assim, saberá o estágio em que o aluno se encontra e o que precisa para concluir o Ensino Médio com as competências e habilidades previstas.

A compreensão e a utilização dos resultados do Spaece longitudinalmente pelos educadores poderão desenvolver no meio escolar uma cultura de avaliação formativa em que todo o processo de desempenho escolar do aluno é monitorado e acompanhado durante três anos, com a perspectiva de fortalecer o planejamento escolar por meio de estratégias metodológicas que propiciem ensino diferenciado aos alunos e leve-os a alcançar aprendizagens significativas neste percurso.

A seguir, realiza-se uma análise longitudinal das médias de proficiência em Língua Portuguesa e Matemática no Spaece, 
no período de 2008-2009, dos alunos do $1^{\circ}$ ano do EM (no ano de 2008) e do $2^{\circ}$ ano do EM (no ano de 2009).

Esses dados serão apresentados em gráficos constando: as médias do Ceará e as médias da $10^{\mathrm{a}}$ Coordenadoria Regional de Desenvolvimento da Educação (Crede), das quais foram selecionadas seis escolas de sua jurisdição de acompanhamento, cujo critério de escolha foi identificar as três escolas que cresceram mais e as três que cresceram menos na proficiência de Matemática do Spaece. No intuito de garantir o anonimato, as escolas foram representadas por letras do alfabeto.

Vale ressaltar que poucas avaliações proporcionam a possibilidade de ter o mesmo grupo de alunos sendo avaliados censitariamente; o desafio será fazer uso desses dados a favor da melhoria da aprendizagem no EM.

\section{ANÁLISE LONGITUDINAL DO SPAECE, PERÍODO 2008-2009}

O gráfico 1 apresenta a evolução dos alunos no $1^{\circ}$ e $2^{\circ}$ anos do EM (2008-2009) por meio de um estudo longitudinal. Neste gráfico, é possível analisar quanto os alunos agregaram de competências e habilidades durante esses dois anos na disciplina de Língua Portuguesa.

GRÁFICO 1 - Estudo longitudinal em Língua Portuguesa através do Spaece (2008-2009)

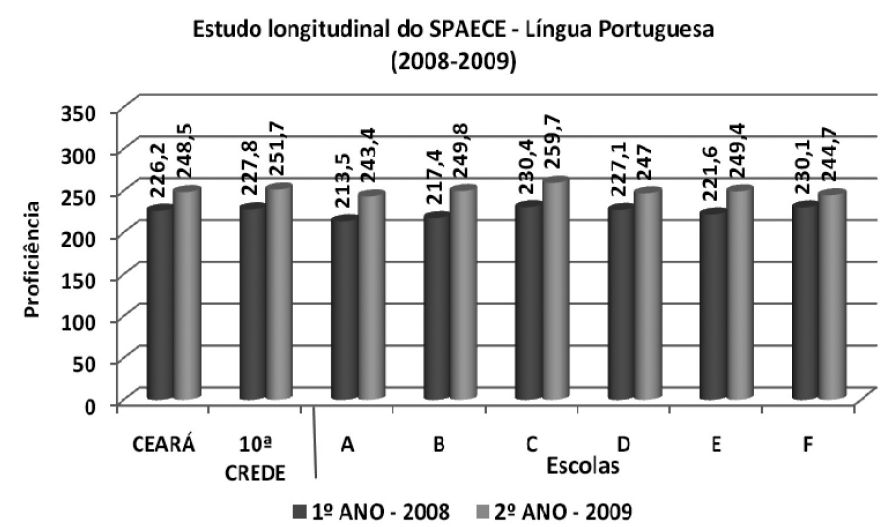


Observa-se que houve crescimento considerável na média do Ceará, da $10^{\mathrm{a}}$ Crede e das escolas, no intervalo de tempo de 2008 a 2009. Algo que pode ter sido alcançado devido a ações estratégicas bem planejadas e desenvolvidas durante o ano de 2009, focadas na melhoria da aprendizagem dos alunos avaliados. Entretanto, o trabalho pedagógico que precisa ser desenvolvido no ano de 2010 junto às turmas do $3^{\circ}$ ano em Língua Portuguesa vai demandar mais esforços, tanto dos professores quanto dos alunos, pois a meta para atingir o nível desejado é de mais de 325 pontos, na escala de proficiência.

Quanto à análise das médias apresentadas no gráfico 1 , podemos diagnosticar que os alunos avaliados longitudinalmente no período de 2008-2009 encontram-se no intervalo do nível de proficiência considerado crítico (225 -- 275), sendo considerados leitores interativos. Na perspectiva de melhor compreensão das competências e habilidades desenvolvidas pelos alunos do $2^{\circ}$ ano do EM em Língua Portuguesa, refletidas através das médias de proficiências apresentadas acima no gráfico, segue o quadro 1 com o perfil do aluno atrelado ao nível de proficiência.

QUADRO 1 - Competências e habilidades que os alunos dominam em Língua Portuguesa

\begin{tabular}{|c|c|c|}
\hline \multicolumn{3}{|c|}{ OS ALUNOS DOMINAM EM LÍNGUA PORTUGUESA } \\
\hline Intervalo & Perfil & Descrição sintética \\
\hline 225 a 275 & Leitor interativo & $\begin{array}{l}\text { Diferencia-se do leitor ativo por possuir } \\
\text { uma maior experiência de leitura, o que } \\
\text { permite que mobilize estratégias mais } \\
\text { sofisticadas para estabelecer relações } \\
\text { entre partes de um texto no processo de } \\
\text { produção de sentidos para o que lê. Por } \\
\text { essa razão, adota uma postura interativa } \\
\text { com o conteúdo de textos de diferentes } \\
\text { gêneros que circulam nas várias esferas } \\
\text { sociais. }\end{array}$ \\
\hline
\end{tabular}

Fonte: Ceará (2008b), Boletim Pedagógico de Avaliação: Português, Ensino Médio.

Considerando a descrição das competências e habilidades agregadas ao intervalo apresentado no quadro 1, os alunos das escolas estaduais do EM possuem habilidades que lhes permitem maior interatividade com o texto, porém ainda longe de serem equiparados ao leitor proficiente, 
apresentando um distanciamento considerável das habilidades que deveriam ter ao término do $3^{\circ}$ ano do EM, conforme mostra o quadro a seguir.

QUADRO 2 - Competências e habilidades que os alunos deveriam dominar em Língua Portuguesa

\begin{tabular}{|c|c|c|}
\hline \multicolumn{3}{|c|}{ OS ALUNOS DEVERIAM DOMINAM EM LÍNGUA PORTUGUESA } \\
\hline Intervalo & Perfil & Descrição sintética \\
\hline Acima de 325 & Leitor interativo & $\begin{array}{l}\text { Mobiliza, na leitura de textos de gêneros } \\
\text { variados, um amplo repertório de } \\
\text { conhecimentos linguísticos aliados à } \\
\text { sua experiência de mundo. É capaz } \\
\text { de interagir adequadamente com } \\
\text { textos ligados a diferentes áreas dos } \\
\text { conhecimentos. }\end{array}$ \\
\hline
\end{tabular}

Fonte: Ceará (2008b), Boletim Pedagógico de Avaliação: Português, Ensino Médio.

Em sequência, o desempenho longitudinal dos alunos em Matemática, apresentado no gráfico 2.

GRÁFICO 2 - Estudo longitudinal em Matemática através do Spaece (2008-2009)

Estudo longitudinal do SPAECE - Matemática (2008-2009)

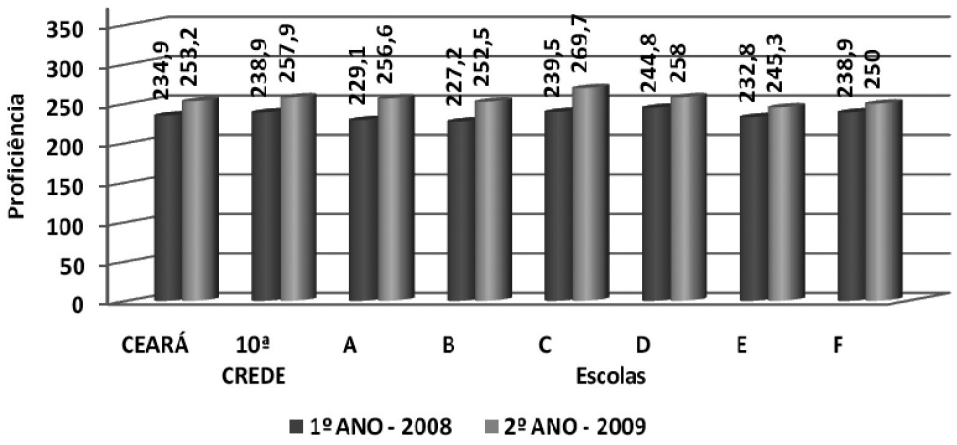

Fonte: Elaboração própria com base em Ceará (2008a; 2009).

Na disciplina de Matemática, houve evolução no desempenho escolar dos estudantes, porém menos significativa do que o crescimento em Língua Portuguesa, o que comprova a dimensão das dificuldades apresentadas pelos alunos em 
Matemática, ocasionadas em sua maior parte pelas dificuldades em leitura e compreensão, prejudicando a aprendizagem em Matemática, além do quesito raciocínio lógico.

Apesar de ter ocorrido o crescimento na proficiência de Matemática no gráfico 2 , os alunos ainda se encontram no nível crítico (250 - 300), com exceção dos alunos da escola "E”, que permaneceram no intervalo muito crítico (abaixo de 250). Para melhor compreender o que eles sabem e deveriam saber, vejamos o quadro 3 a seguir.

QUADRO 3 - Competências e habilidades que os alunos desenvolveram e/ou deveriam ter desenvolvido em Matemática

\begin{tabular}{|c|c|c|}
\hline \multicolumn{3}{|c|}{ OS ALUNOS DOMINAM EM MATEMÁTICA } \\
\hline Intervalo & Perfil & Descrição sintética \\
\hline 225 até 275 & Grau III & $\begin{array}{l}\text { Os alunos identificam características } \\
\text { relacionadas aos sólidos geométricos e } \\
\text { suas planificações; diferenciam poliedros } \\
\text { de corpos redondos; resolvem problemas } \\
\text { envolvendo as quatro operações; } \\
\text { representam números racionais na forma } \\
\text { fracionária com apoio de representação } \\
\text { gráfica; calculam porcentagens simples; } \\
\text { números inteiros e decimais na reta } \\
\text { numérica; relacionam gráficos entre si e } \\
\text { com dados apresentados na forma textual } \\
\text { e/ou tabelas; identificam gráficos de } \\
\text { colunas correspondentes a um gráfico de } \\
\text { setores; localizam dados em tabelas de } \\
\text { múltiplas entradas. }\end{array}$ \\
\hline \multicolumn{3}{|c|}{ OS ALUNOS DEVERIAM DOMINAM EM MATEMÁTICA } \\
\hline Intervalo & Perfil & Descrição sintética \\
\hline Acima de 325 & Leitor interativo & $\begin{array}{l}\text { Resolvem problemas envolvendo o } \\
\text { teorema de Pitágoras, a lei angular } \\
\text { de Tales e aqueles que utilizam a } \\
\text { razão de semelhança entre polígonos; } \\
\text { estabelecem relações utilizando elementos } \\
\text { geométricos, como raio, diâmetro e } \\
\text { cordas; diferenciam figuras; representam } \\
\text { e localizam pontos, retas e circunferências } \\
\text { no plano cartesiano; resolvem problemas } \\
\text { envolvendo relações métricas em um } \\
\text { triângulo retângulo; resolvem problemas } \\
\text { envolvendo as grandezas de volume e } \\
\text { capacidade estabelecendo a relação } \\
\text { entre suas medidas; calculam o perímetro } \\
\text { de polígonos sem o apoio de malhas } \\
\text { quadriculadas; áreas de semicírculo e } \\
\text { trapézio retângulo e volume. }\end{array}$ \\
\hline
\end{tabular}

Fonte: Ceará (2008c), Boletim Pedagógico de Avaliação: Português, Ensino Médio.

Vale ressaltar que os alunos do EM têm três anos para desenvolver as competências e habilidades previstas para o EM, 
portanto é fundamental que o professor das disciplinas de Língua Portuguesa e Matemática acompanhe o grau evolutivo de seus alunos de uma série para outra, localize-os na escala de proficiência, na perspectiva de compreender o que desenvolveram e quais as dificuldades apresentadas que os impedem alcançar o nível adequado ao final do EM.

Os gráficos 3 e 4 representam o crescimento nas médias de proficiência em Língua Portuguesa e Matemática. Analisa-se o que este crescimento representa em percentual e quanto os alunos necessitam de acréscimo no ano de 2010 para concluir o $3^{\circ}$ ano do EM com o nível desejado.

\section{CRESCIMENTO LONGITUDINAL, EXPECTATIVAS PARA O 3 ANO DO ENSINO MÉDIO}

O fato de o estado do Ceará ter crescido tanto em Língua Portuguesa quanto em Matemática indica que grande parte das escolas está trabalhando concentrada em suas ações estratégicas cotidianas para alcançar a melhoria do desempenho escolar dos alunos. Os gráficos 3 e 4 a seguir representam o crescimento longitudinal de Língua Portuguesa e Matemática no período 2008-2009.

GRÁFICO 3 - Crescimento longitudinal em Língua Portuguesa e Matemática, período 2008-2009

CRESCIMENTO LONGITUDINAL 2008-2009 (\%)

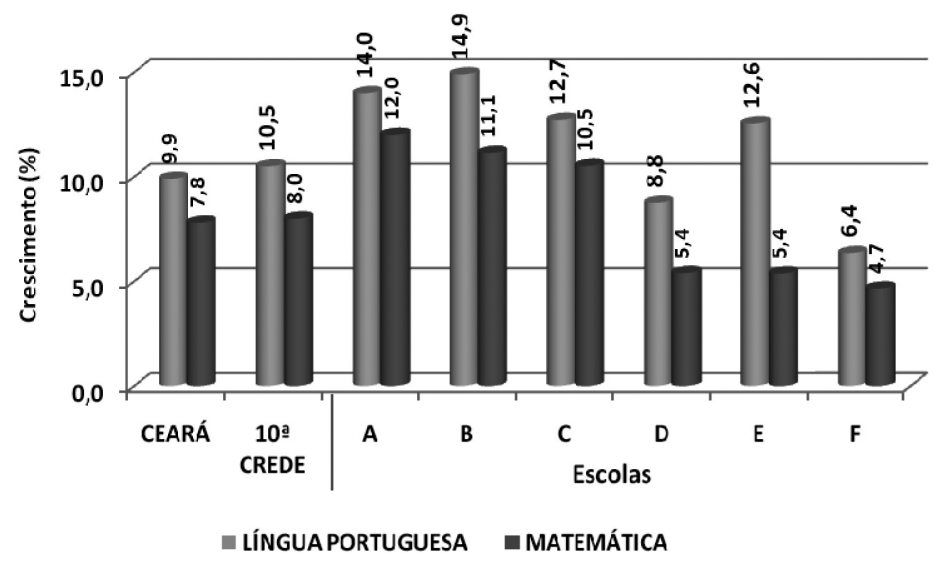


A média de proficiência dos alunos em Língua Portuguesa supera o crescimento em Matemática, em alguns casos mais de $3 \%$, como as escolas B, D e E, conforme evidenciado acima. Porém, não se pode esquecer que nos gráficos vistos anteriormente, que representavam as proficiências nas duas disciplinas avaliadas no Spaece, a distância de onde estava para onde deveria chegar era significativo. As escolas da $10^{\mathrm{a}}$ Crede A, B e $C$ são as que mais cresceram na região em Matemática. No outro extremo, temos as escolas D, E e F, que tiveram menor crescimento.

No gráfico 4, estão as metas estabelecidas para se alcançar o nível desejado para a conclusão do $3^{\circ}$ ano em Língua Portuguesa e Matemática, estabelecido pela escala do Spaece.

GRÁFICO 4 - Crescimento longitudinal necessário em 2010 para

Crescimento longitudinal necessário para o ano de $\mathbf{2 0 1 0}$

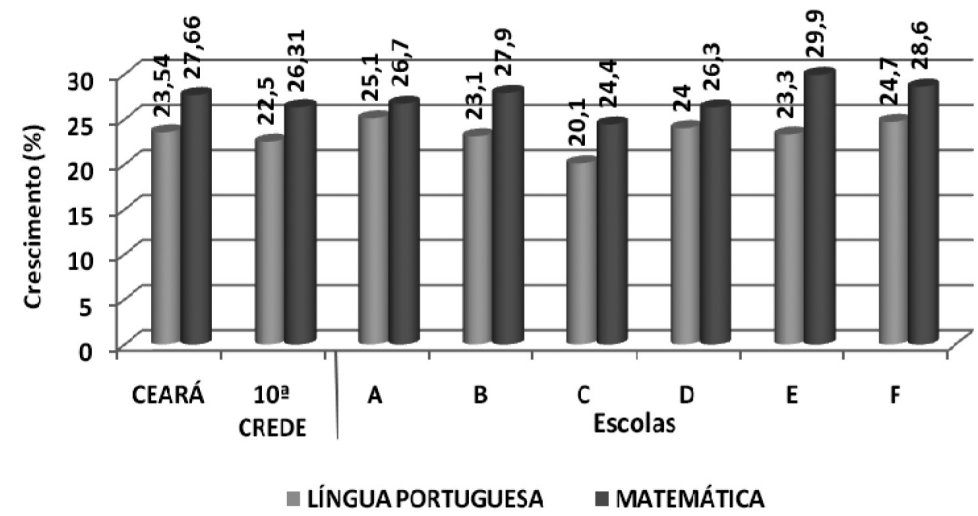

Fonte: Elaboração própria com base em Ceará (2008a; 2009).

A necessidade de melhoria do desempenho escolar dos alunos para ambas as disciplinas supera a marca de $20 \%$, sendo mais delicada a situação de Matemática, que em alguns casos se aproxima de $30 \%$. Levando em consideração quanto cresceu do $1^{\circ}$ ano para o $2^{\circ}$ ano do EM, pode-se pressupor que será improvável fechar o ciclo dos três anos do EM com o nível mínimo adequado, dado o crescimento em percentual do Ceará e da $10^{\mathrm{a}}$ Crede apresentado no gráfico 3, que não ultrapassa $10 \%$ e $11 \%$, respectivamente.

Entretanto, através do trabalho pedagógico cotidiano constante, realizado em uma perspectiva formativa, há 
condições de continuar o crescimento, podendo este superar a marca do ano de 2009. Para um trabalho mais eficaz, será necessário que os professores tenham conhecimento tanto de onde seus alunos se encontram na escala de proficiência como de aonde precisam chegar, com clareza de quais competências e habilidades eles precisam desenvolver até a conclusão do ano letivo. Assim, é interessante que as Matrizes de Referências utilizadas no Spaece sejam integradas ao currículo do EM.

É importante frisar que não está sendo dada exclusividade ao uso das matrizes, considerando que estas só avaliam as competências e habilidades mensuráveis; entretanto, na organização do plano de curso realizado no início do ano letivo, o professor, conhecedor das matrizes, poderá associar os descritores ao conteúdo que será lecionado, auxiliando-o na melhoria da elaboração das atividades do aluno, bem como da prática docente. Além desta integração ao currículo, o professor precisa ter ciência da evolução do percentual de acertos por descritor do aluno no decorrer do ciclo ( $1^{\circ}$ e $2^{\circ}$ anos) do EM, conforme apresentado a seguir.

\section{EVOLUÇÃO DO PERCENTUAL DE ACERTOS POR DESCRITOR}

O crescimento evidenciado nos gráficos 1 a 4 entra em conflito quando se analisa o percentual de acertos por descritor através dos eixos ou temas das Matrizes de Referência em Língua Portuguesa e Matemática. Vale lembrar que esta análise foi possível em razão de se tratar do mesmo grupo de alunos.

A seguir são apresentados os gráficos referentes ao percentual de acertos nos eixos de Língua Portuguesa comuns no Spaece no período 2008-2009. 
GRÁFICO 5 - Percentual de acertos dos alunos nos descritores do eixo 1 de Língua Portuguesa, período 2008-2009

Eixo 1 - Quanto à informação do texto verbal e/ ou não verbal

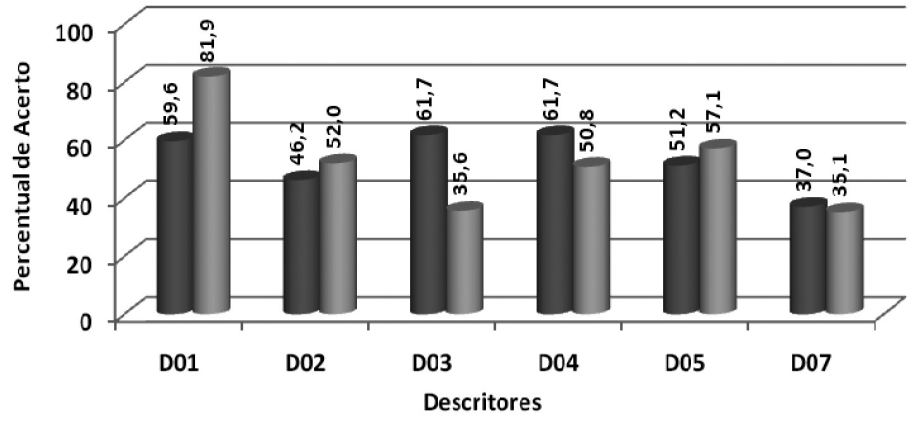

$\because$ 1ANO $\because$ 2OANO

Fonte: Elaboração própria com base em Ceará (2008a; 2009)

Dos seis descritores apresentados no gráfico 5 , constata-se crescimento em D01, D02 e D05 de respectivamente $22,3 \%, 5,8 \%$ e $5,9 \%$. Estes descritores avaliam se os alunos desenvolveram as habilidade de localizar informações explícitas em textos, inferir informação em texto verbal e identificar o tema ou assunto do texto. Nos demais descritores, os alunos do $2^{\circ}$ ano apresentam decréscimo significativo, chegando a $26,1 \%$ no descritor D03, que está associado à habilidade do aluno em identificar qual o sentido da palavra ou expressões utilizadas.

No gráfico 5, é possível constatar que o grau de dificuldade de alguns descritores acentuou-se de um ano para outro. Lembrando que, apesar de os descritores fazerem parte da mesma matriz de referência utilizada na elaboração das provas do Spaece, o grau de complexidade é equivalente à série/ano avaliado.

Isso significa que, no decorrer do ano em estudo, o aluno aprofundará mais seus conhecimentos em relação a determinados conteúdos, o que implicará a melhoria das habilidades desenvolvidas, dando-lhe a condição de resolver itens mais complexos, fato que não ocorria segundo os dados coletados. 
GRÁFICO 6 - Percentual de acertos dos alunos nos descritores do eixo 2 de Língua Portuguesa, período 2008-2009

Eixo 2 - Quanto aos gêneros associados às sequências discursivas básicas

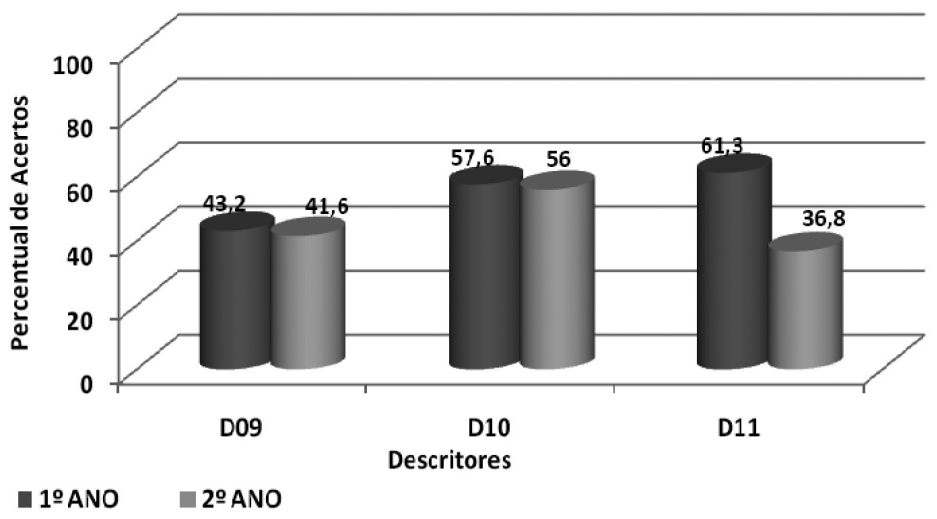

Fonte: Elaboração própria com base em Ceará (2008a; 2009).

No eixo 2, apresentado pelo gráfico 6, o percentual de acertos decresce de um ano para outro. Em destaque, o descritor D11 com 24,5\% negativo de crescimento do ano de 2008 para 2009. Este descritor está relacionado à condição do aluno de identificar em uma narrativa seus personagens, o papel de cada um na história, bem como a ideia central, entre outras informações.

Os resultados do descritor D13 no gráfico 7 demonstram um percentual de crescimento em acertos significativo de 31,7\%. Isso significa, segundo a Matriz de Referência de Língua Portuguesa do Spaece (CEARÁ, 2009), que os alunos estão mais hábeis em reconhecer as variadas formas textuais pelas quais um tema/informação pode ser tratado. 
GRÁFICO 7 - Percentual de acertos dos alunos nos descritores dos eixos 3 e 4 de Língua Portuguesa, período 2008-2009

Eixo 3 - Quanto às relações entre textos

Eixo 4 - Quanto às relações de coesão e coerência

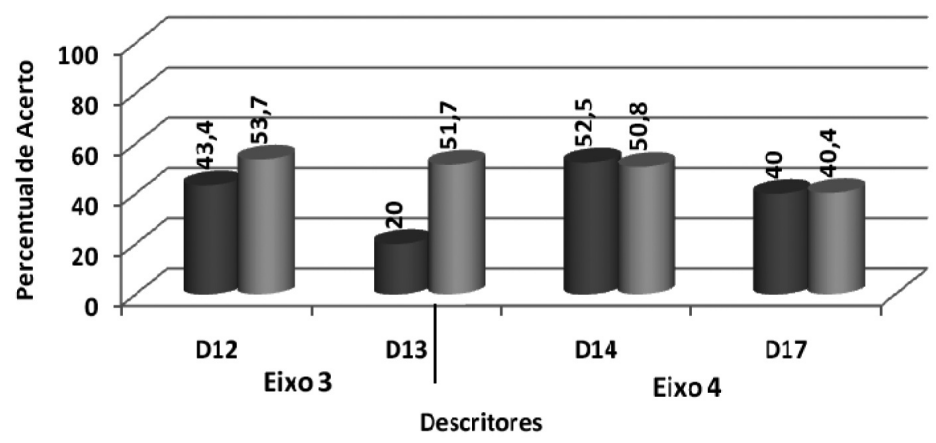

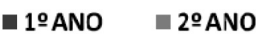

Fonte: Elaboração própria com base em Ceará (2008a; 2009).

Tratando-se dos demais descritores, houve aumento não tão significativo como o D13, com exceção do descritor D14, que caiu $1,7 \%$.

GRÁFICO 8 - Percentual de acertos dos alunos nos descritores dos eixos 3 e 4 de Língua Portuguesa, período 2008-2009

Eixo 5 - Quanto aos recursos expressivos utilizados no texto Eixo 6 - Quanto aos aspectos sociais da linguagem

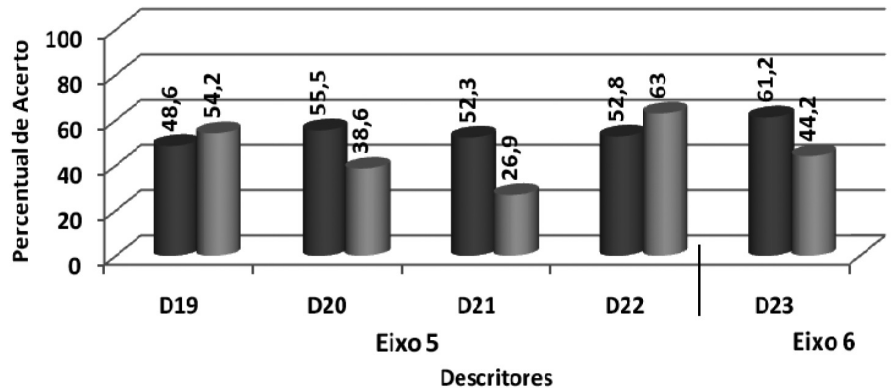

-19ANO

Fonte: Elaboração própria com base em Ceará (2008a; 2009).

Nos eixos 5 e 6, os percentuais de acertos decaem nos descritores D20, D21 e D23 em 16,9\%, 25,4\% e 17\%, nesta ordem. O crescimento nos descritores D19 e D22 de 5,6\% e 
10,2\%, respectivamente, é razoável, mas ainda deixa a desejar, considerando o número de alunos que não conseguiram desenvolver tal habilidade. É possível verificar nos gráficos 9 e 10, a seguir, que o grau de dificuldade dos alunos em Matemática tem-se acentuado em vários descritores, estando o percentual de acertos da maior parte dos descritores do eixo 1 abaixo de $30 \%$, quanto aos demais eixos seis, descritores estão abaixo de $40 \%$.

GRÁFICO 9 - Percentual de acertos dos alunos nos descritores do eixo 1 de Matemática, período 2008-2009

Eixo 1 - Interagindo com os números e funções

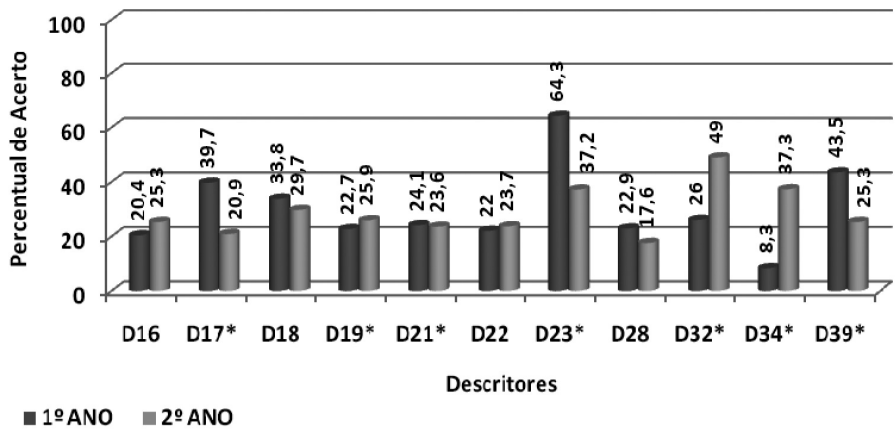

Fonte: Elaboração própria com base em Ceará (2008a; 2009).

GRÁFICO 10 - Percentual de acertos dos alunos nos descritores dos eixos 2, 3 e 4 de Matemática, período 2008-2009

Eixo 2- Convivendo com a Geometria; Eixo 3 - Vivendo as medidas; Eixo 4 - Tratamento da informação.

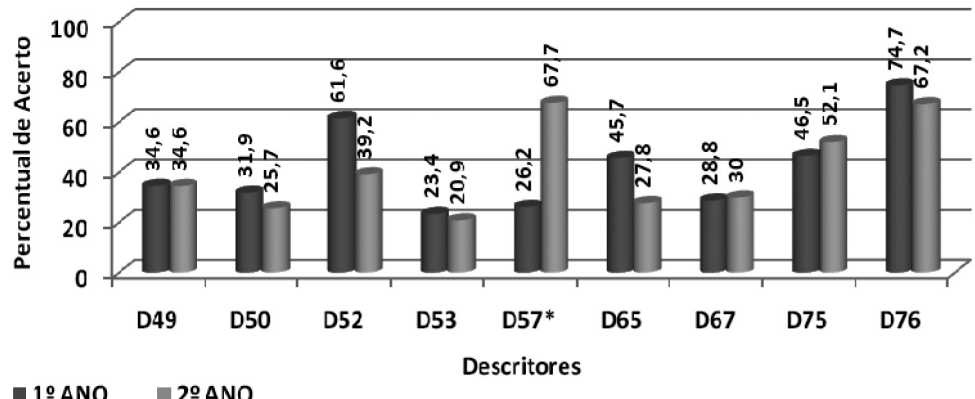

\footnotetext{
Fonte: Elaboração própria com base em Ceará (2008a; 2009).
}

Os descritores com o símbolo do asterisco representam as habilidades utilizadas na avaliação do $2^{\circ}$ ano do EM (2009) com o 
objetivo de equalizar e comparar com a escala adotada pelo Saeb e as demais séries do EM (CEARÁ, 2009). Entre esses descritores, observa-se o crescimento significativo no eixo 1 de mais de $20 \%$ em D32 e D34, porém ainda abaixo de 50\% de acertos total, e no eixo 2 o descritor D57 apresenta aumento de 41,5\%, este último referindose à habilidade do aluno de localizar pontos no plano cartesiano.

Os descritores, presentes no gráfico 9, que decresceram, expressam as dificuldades dos alunos com resolução de situações-problema envolvendo cálculo de porcentagem (D17), variação proporcional (D18) e números reais envolvendo suas operações (D23), bem como no reconhecimento da representação algébrica ou gráfica de função polinomial de $2^{\circ}$ grau (D28) e resolução de problemas com situações contextualizadas envolvendo propriedades de uma progressão aritmética ou geométrica (D39).

Em destaque, o crescimento dos alunos na habilidade de resolverem situações-problema que envolvem os pontos de máximo ou de mínimo no gráfico de uma função polinomial do $2^{\circ}$ grau (D32) e resolução de problemas envolvendo função exponencial. Porém, apesar do crescimento, os alunos avaliados ainda têm o percentual de acertos abaixo de $50 \%$.

No gráfico 10, há crescimento negativo no percentual de acertos dos alunos avaliados no eixo 2, Convivendo com a Geometria, relacionados à habilidade de compreensão do Teorema de Pitágoras para resolução de situações-problema (D50), indentificar planificações de alguns poliedros e/ou corpos redondos (D52) e resolução de problemas envolvendo razões trigonométricas (seno, cosseno e tangente) (D53). O único descritor deste eixo que supera a marca de 60\% está relacionado à habilidade do aluno em identificar a localização de pontos no plano cartesiano (D57).

No eixo 3, Vivendo as medidas, há decréscimo no percentual de acertos do descritor que avalia se o aluno sabe calcular o perímetro de figuras planas (D65). No que se refere ao eixo 4, Tratamento da informação, apesar de apresentar $67,2 \%$ no percentual de acertos em D76, relacionado à habilidade de resolução de problemas envolvendo informações apresentadas em tabelas ou gráficos, ocorre decréscimo em relação ao $1^{\circ}$ ano do EM.

$\mathrm{Na}$ análise destes resultados, é perceptível a falta de apropriação de alguns conhecimentos na disciplina de 
Matemática, inerentes ao conteúdo do Ensino Fundamental, o que dificulta a aprendizagem do aluno no EM, pois à medida que os conteúdos vão sendo aprofundados no decorrer das seriações do EM os alunos sentem dificuldades de progredir devido às lacunas existentes dos anos anteriores.

\section{CONCLUSÃO}

As últimas edições do Spaece revelou à comunidade escolar um retrato das dificuldades dos alunos no decorrer dos três anos do EM. Esse retrato identifica o nível da aprendizagem do estudante na escala de proficiência, ou seja, as competências e habilidades desenvolvidas na série/ano avaliado, bem como as que deveriam ter sido desenvolvidas pelos alunos para que fossem considerados no nível adequado.

O planejamento escolar será enriquecido se os professores de Língua Portuguesa e Matemática se apropriarem destes dados, identificando quais são as dificuldades de cada um de seus alunos, e a partir destas traçar metodologias diferenciadas a serem desenvolvidas na sala de aula. Isto somente é possível devido à evolução do Spaece ao longo de suas edições, pois seus resultados, divulgados em boletins pedagógicos pela Secretaria da Educação do Estado do Ceará, apresentam: a média por série/ ano da escola; o percentual de acertos em cada descritor das Matrizes de Referência para avaliação em Língua Portuguesa e Matemática; e um banco de dados com os resultados por aluno/ série avaliado na escola que especifica por aluno: os descritores acertados e aqueles em que não houve acerto, a proficiência em cada disciplina avaliada, entre outras informações.

Assim, a apropriação desses dados pelos professores e gestores é o grande desafio a ser superado no âmbito escolar para que se viabilize a melhoria do ensino por meio de metas préestabelecidas a serem alcançadas através de ações estratégicas com foco nas necessidades dos alunos. Nesta perspectiva, o estudo longitudinal passa a ser mais um recurso para a análise situacional dos alunos no decorrer dos três anos do EM. A monitoria e o acompanhamento evolutivo dos níveis de aprendizagem de cada aluno/série por parte dos docentes e gestores focará o 
planejamento pedagógico em ações centradas nas reais dificuldades de aprendizagem dos alunos do EM.

\section{REFERÊNCIAS BIBLIOGRÁFICAS}

CEARÁ. Secretaria da Educação. Boletim de Resultados Gerais. Spaece - 2009. Universidade Federal de Juiz de Fora, Faculdade de Educação, CAEd. v. 2 (jan./dez. 2009), Juiz de Fora, 2009 - Anual.

Secretaria da Educação. Sistema Permanente de Avaliação da Educação Básica do Ceará - Spaece 2008. Boletim Regional de Resultados: $1^{\mathrm{a}}, 2^{\mathrm{a}}$ e $3^{\text {a }}$ Séries do Ensino Médio. Universidade Federal de Juiz de Fora, Faculdade de Educação, CAEd. v. 1 (jan./dez. 2008), Juiz de Fora, 2008a - Anual.

. Secretaria da Educação. Sistema Permanente de Avaliação da Educação Básica do Ceará - Spaece 2008. Boletim Pedagógico de Avaliação: Português, Ensino Médio. Universidade Federal de Juiz de Fora, Faculdade de Educação, CAEd. v. 1 (jan./dez. 2008), Juiz de Fora, 2008b - Anual.

Secretaria da Educação. Sistema Permanente de Avaliação da Educação Básica do Ceará - Spaece 2008. Boletim Pedagógico de Avaliação: Matemática, Ensino Médio. Universidade Federal de Juiz de Fora, Faculdade de Educação, CAEd. v. 1 (jan./dez. 2008), Juiz de Fora, 2008c - Anual.

SANTOS, Francesca Danielle Gurgel dos. Impactos gerados pelo Sistema Permanente de Avaliação Básica do Estado do Ceará (Spaece) na melhoria do ensino e aprendizagem no ensino médio. 2010. 190f. Dissertação (Mestrado em Educação) - Universidade Federal do Ceará, Fortaleza, 2010.

Análise longitudinal do nível de proficiência dos alunos do ensino médio no SPAECE, período 2008-2009. In: CONGRESSO INTERNACIONAL EM AVALIAÇÃO EDUCACIONAL, V, 2010, Fortaleza. Anais... Fortaleza: Imprece, 2010.

VIANNA, Heraldo M. Avaliação educacional: teoria, planejamento, modelos. São Paulo: Ibrasa, 2000.

\section{FRANCESCA DANIELLE GURGEL DOS SANTOS}

Professora da Rede Estadual do Ceará. Mestre e

Doutoranda em Educação Brasileira pela Universidade

Federal do Ceará (UFC)

dani_gurgel@yahoo.com.br 


\section{MARIA ISABEL FILGUEIRAS LIMA CIASCA}

Professora Associada do Departamento de Fundamentos da Educação da Faculdade de Educação (FACED) da Universidade Federal do Ceará (UFC), Diretora da Faculdade de Educação (FACED) da UFC, Mestre em Educação, Arte e História da Cultura pela Universidade Presbiteriana Mackenzie, Doutora em Educação Brasileira pela UFC isabelfil@uol.com.br 